

\title{
Influence of gender on delays and early mortality in ST-segment elevation myocardial infarction: Insight from the first French Metaregistry, 2005-2012 patient-level pooled analysis
}

Stephane Manzo-Silberman, Francis Couturaud, Sandrine Charpentier, Vincent Auffret, Carlos El Khoury, Hervé Le Breton, Loic Belle, Stéphanie Marlière, Marianne Zeller, Yves Cottin, et al.

\section{- To cite this version:}

Stephane Manzo-Silberman, Francis Couturaud, Sandrine Charpentier, Vincent Auffret, Carlos El Khoury, et al.. Influence of gender on delays and early mortality in ST-segment elevation myocardial infarction: Insight from the first French Metaregistry, 2005-2012 patient-level pooled analysis. International Journal of Cardiology, 2018, 262, pp.1-8. 10.1016/j.ijcard.2018.02.044 · hal-01730188

\section{HAL Id: hal-01730188 https://u-bourgogne.hal.science/hal-01730188}

Submitted on 19 Jun 2018

HAL is a multi-disciplinary open access archive for the deposit and dissemination of scientific research documents, whether they are published or not. The documents may come from teaching and research institutions in France or abroad, or from public or private research centers.
L'archive ouverte pluridisciplinaire HAL, est destinée au dépôt et à la diffusion de documents scientifiques de niveau recherche, publiés ou non, émanant des établissements d'enseignement et de recherche français ou étrangers, des laboratoires publics ou privés. 
Influence of gender on delays and early mortality in ST-Segment Elevation Myocardial Infarction: Insight from the first French Metaregistry, 2005-2012 patientlevel pooled analysis.

Stéphane Manzo-Silberman ${ }^{1}$, MD, Francis Couturaud ${ }^{2}$, MD, PhD, Sandrine Charpentier $^{3}$, MD, PhD, Vincent Auffret ${ }^{4}$, MD, Carlos El Khoury ${ }^{5}$, MD, PhD, Hervé Le Breton $^{4}$, MD, PhD, Loïc Belle ${ }^{6}$, MD, Stéphanie Marlière ${ }^{7}$, MD, Marianne Zeller ${ }^{8}$, PHD, Yves Cottin', MD, PhD, Nicolas Danchin ${ }^{10}$, MD, PhD, Tabassome Simon ${ }^{11}$, MD, PhD, François Schiele $^{12}$, MD, PhD, Martine Gilard ${ }^{13}$ MD, PhD.

1: Department of Cardiology, CHU Lariboisière, AP-HP, Paris VII University, INSERM UMRS 942, Paris France

2: Department of Internal Medicine and Chest Diseases, EA3878, CIC-INSERM1412, Brest University Hospital, European University of Occidental Brittany, Brest, France

3: for the RESCA+31 Registry: Emergency Department, Rangueil University Hospital, Toulouse, France; Toulouse III Paul Sabatier University, Toulouse, France; Team 5, INSERM UMR 1027, Toulouse, France

4: for the ORBI Registry, Cardiology and Vascular Diseases Department, Rennes University Hospital, Rennes, France; Rennes 1 University, LTSI, Rennes, F-35000, France; 3 INSERM, U1099, Rennes, France

5: for the RESCUe Registry,Emergency Department and RESCUe Network, Lucien Hussel Hospital, Vienne, France

'; for the RESURCOR Registry, Cardiology Department, Annecy Hospital, Annecy, France 
7: for the RESURCOR Registry, Cardiology Department, University Hospital, Grenoble, France

8: for the RICO Registry, Laboratory of Cardiometabolic Physiopathology and Pharmacology, University of Burgundy, Dijon, France

9: for the RICO Registry, Department of Cardiology, University Hospital, Dijon, France

10: for the FAST Registry, Department of Cardiology, Hôpital Europeen Georges Pompidou,

Paris Hospitals Board (AP-HP), Paris, France; Paris V University, Paris, France

11: for the FAST Registry, Department of Pharmacology-URCEST, Paris Hospitals Board (AP-HP), Paris, France; UPMC-Paris 06, Paris, France; INSERM U-1148, Paris, France

${ }^{12}$ : for the FComt Registry, Department of Cardiology, University Hospital Jean Minjoz, EA3920, Besançon, France.

13: Cardiology Department, Brest University Hospital, EA 4324, European University of Occidental Brittany, Brest, France.

All authors take responsibility for all aspects of the reliability and freedom from bias of the data presented and their discussed interpretation.

Corresponding author: Stephane Manzo-Silberman, Cardiology Department, Lariboisière University Hospital, Paris Hospitals Board (AP-HP), Paris VII University; INSERM UMRS 942, Paris France; tel.:0033 6611353 34/ 0033 149958224; e-mail: stephane.manzosilberman @aphp.fr

Conflict of interest: The authors report no relationships that could be construed as a conflict of interest. 


\begin{abstract}
:
Background: Women show greater mortality after acute myocardial infarction. We decided to investigate whether gender affects delays and impacts in-hospital mortality in a large population.
\end{abstract}

Methods and results: We performed $a$ patient-level analysis of 7 French MI registries from different regions from January 2005 to December 2012. All patients with acute STEMI were included within12 hours from symptom onset and a first medical contact with a mobile intensive care unit an emergency department of a hospital with percutaneous coronary intervention facility . Primary study outcomes were STEMI, patient and system, delays. Secondary outcome was in-hospital mortality. 16,733 patients were included with 4,021 females (24\%). Women were significantly older (mean age 70.6 vs 60.6), with higher diabetes (19.6\% vs $15.4 \%)$ and hypertension rates (58.7\% vs $38.8 \%)$. Patient delay was longer in women with adjusted mean difference of $14.4 \mathrm{~min}(\mathrm{p}<0.001)$; system delay did not differ. In-hospital death occurred 3 times more in women. This disadvantage persisted strongly adjusting for age, therapeutic strategy and delay with a $1.85(1.32-2.61)$ adjusted hazard ratio.

Conclusions: This overview of 16,733 real-life consecutive STEMI patients in prospective registries over an extensive period strongly indicates gender-related discrepancies, highlighting clinically relevant delays in seeking medical attention. However, higher in-hospital mortality was not totally explained by clinical characteristics or delays. Dedicated studies of specific mechanisms underlying this female disadvantage are mandatory to reduce this gender gap.

Keywords: STEMI; Gender issues; Clinical research; 
Coronary artery disease is the leading cause of mortality in Western countries ${ }^{1,2}$. Women have been shown to be at greater risk of dying after acute myocardial infarction (MI), particularly in STsegment elevation MI (STEMI) ${ }^{3-14}$, with frequently observed poorer prognosis and higher death rates, especially during in-hospital and short-term follow-up ${ }^{6,8,13,15-19}$. Sex differences in STEMI have been reported regarding baseline characteristics, with greater age and higher prevalence of type- 2 diabetes, hypertension and dyslipidemia in females ${ }^{3,4,7,11,18,20-23}$. Procedural characteristics also vary according to gender, with less use of pre-hospital fibrinolysis and of invasive strategies. However, the impact of gender appears to diminish after control for age and comorbidities ${ }^{7,11}$. Nonetheless, registry results highlight differences in time management ${ }^{21,24,25}$, mainly regarding call time and catheterization laboratory (cath lab) transfer time, with longer delays for females, but again modified by adjustment. Time to treatment is known to be an essential predictor of fatal outcome in STEMI patients ${ }^{26-32}$. However, the respective roles of each component of time to treatment need to be specified: the patient's delay in seeking medical attention and the health system's delays (door-to-balloon time). These delays have to be analyzed in the contemporary setting of organized networks and widespread use of percutaneous coronary intervention (PCI) for STEMI.

The present study investigated whether gender influenced STEMI delays (patient and system delays and ischemic time), which delay was the most influenced, and whether the effect of gender on early outcome after STEMI, in terms of in-hospital mortality, was mediated by longer delays.

A patient-level pooled analysis was therefore performed, including patients from French registries (the French Metaregistry collection) over a long period of time and from different regions, to investigate the impact of gender, with increased statistical power by including real-world STEMI patients treated by primary PCI (pPCI) and/or by fibrinolysis. It was hypothesized that this data collection would enable precise study of the various components of STEMI delays and of whether, after adjustment, these delays are critically different according to gender and clinically relevant.

\section{Methods}

\section{Registries:}


MI registries were developed to provide updated, exhaustive and validated data on morbidity and mortality from cardiovascular causes, to define patient profiles, and to identify therapeutic strategies in MI. For many years in France, regional registries have been kept up, some as part of care networks of cardiologists and emergency physicians, to monitor practice and improve the care process, including rates and forms of reperfusion ${ }^{33}$.

The present study pooled patient-level datato provide large validated data on the acute issue of gender discrepancies. This surrogate of a national database provides, for the first time, a complete overview, allowing comparison with data collected in other countries, and should help to design strategies for improvement and educational campaigns.

All the principal investigators in all existing French registries and surveys, except one, agreed to participate and share patient-level data (online supplement eTable 1).

All the registries, despite some methodological differences, used the same care logistics protocols, with similar networking between hospitals and pre-hospital medical services. They all used the same definition of STEMI, following national and international guidelines ${ }^{34}$. Particular attention was paid to homogeneity of data. Data characteristics are summarized in the online supplement. These registries collect data from very varying regions, differing in population density, urban or rural predominance, geographical characteristics, and availability and distribution of interventional cardiology centers. This diversity should allow extrapolation of the present results to other countries.

\section{Patients}

The study population consisted of all patients included in the participant registries from January 2005 to December 2012. STEMI was defined by typical chest pain lasting more than 20 minutes and less than 12 hours and ST elevation $>0.2 \mathrm{mV} \_0.2 \mathrm{mV}$ in men or $0.15 \mathrm{mV}$ in women in $\geq 2$ precordial leads or $>0.1 \mathrm{mV}$ in $\geq 2$ frontal leads or left bundle branch block. Only patients whose first medical contact was an emergency department with PCI facility or a mobile intensive care unit (MICU) were included. The French emergency healthcare system is highly medicalized: in case of chest pain, patients are 
encouraged to call the emergency medical dispatch center (by phoning 15 or 112); after assessing the probability of acute MI, the emergency physician can dispatch a MICU with a physician on board. Patients presenting out-of-hospital cardiac arrest prior to the first medical contact (FMC) were excluded. To maintain data consistency for the examination of trends, patients directly admitted to a coronary care unit were also excluded.

Whereas registries collect data on a standardized set of clinical, demographic and procedural variables along with in-hospital outcome, the present study focused only on data for demographics, time to call and to treatment, reperfusion strategy, initial antithrombotic drugs (when known) and in-hospital mortality.

\section{Outcomes}

The primary outcome measures of the study were the various STEMI delays ${ }^{34}$ : patient delay, from symptom onset until call to emergency service (15 or 112) or until presentation at the emergency department (as reported by the patient); system delay, from FMC (presentation at the emergency department or arrival of the MICU team) to thrombolysis or pPCI puncture; and total ischemic time, from symptom onset to pPCI or thrombolysis, defined as time of puncture, as reported in all the registries. The influence of gender on these delays was assessed, initially without adjustment, and then stratified by age and risk factors.

The secondary outcome was in-hospital mortality, which included death from any cause occurring during the index hospitalization for STEMI, with assessment of the influence of gender, age risk factors, therapeutic strategy and delays.

Using this unique innovative French database, regional differences were represented. Changes were assessed over the whole from 2005 to 2012.

\section{Data management}

For each patient, standardized data collection was performed using the specific registry case report form (CRF). Demographic, clinical, delay and treatment data, drugs and reperfusion strategies 
and in-hospital mortality were collected prospectively by emergency physicians and cardiologists and recorded on each registry's CRF. CRFs were anonymous, in accordance with the French data protection commission (Commission Nationale de l'Informatique et des Libertés) guidelines; data collection complied with the Declaration of Helsinki and was approved by local institutional review boards. For each registry, a research assistant checked completeness of data and follow-up. Data quality was regularly controlled within each registry, with regular audits confirming reproducibility.

\section{Study design and oversight}

The study was designed by the first and last author and approved by the scientific committee. The scientific committee, composed of principal or representative investigators of each participant registry, reviewed and approved the proposal.

The authors vouch for the accuracy and completeness of the data and the analysis.

\section{Statistical analysis}

Patient characteristics at baseline were described for the study population and for each group (male, female). Continuous variables were reported as mean plus or minus standard deviation and categorical variables as absolute and relative frequencies (percentages). Categorical variables were compared between men and women using chi-square test, or Fisher's exact test as appropriate; continuous variables were compared using Student's t test for normal distributions or on non-parametric tests for non-normal distributions. Normal distribution was assessed for each variable on Shapiro-Wilk test.

Mean delays (i.e., patient delay, ischemic time and system delay) were compared between men and women using Student's t test and mean differences were reported with $95 \%$ confidence intervals. The estimated marginal means of the delays, plus or minus standard error, adjusted on age, region, year of enrolment and emergency call (yes/no), were compared using a generalized linear model and mean differences were reported with $95 \%$ confidence intervals. Means were considered statistically different when the p-value was less than 0.05 . 
To determine risk factors for in-hospital mortality, univariable analysis was performed for each possible factor, using a logistic regression model. Variables with prevalence $>3 \%$ and $p$-value $<0.15$ were included in a multivariable logistic regression model, after checking correlations between variables of interest; if variables were significantly correlated, the variable to be included in the multivariate model was selected according to clinical relevance or on the Akaike information criterion for multivariable models, performed on the correlating variables. Interactions were also tested; in case of significant interaction between variables, an interaction term was included in the multivariate model. All tests were 2 tailed. A variable was considered to be an independent risk factor for mortality when the p-value was less than 0.05 in the multivariate model. Statistical analyses were performed using SPSS software (version 20.0; SPSS Inc., Chicago, Illinois).

\section{Results}

Between 2005 and 2012, 18,618 consecutive STEMI patients were included prospectively in the 7 participating French registries (online supplement eTable 1). Due to the strict exclusion criteria, the population was homogenous and confounding factors linked to modality of inclusion (MICU or interventional cardiology center) were limited.

Within this population, 16,733 STEMI patients with call delay <12 hours were included in the study: 4,021 female and 12,712 male. Women constituted similar proportions, whichever the registry, from $21.7 \%$ (RESURCOR) to $29.9 \%$ (F Comt) $(\mathrm{p}=0.48)$, and whichever the year of inclusion.

\section{Patient characteristics}

Baseline characteristics of the 16,733 consecutive STEMI patients are presented in Table 1. Females were significantly older than males $(70.6 \pm 14$ vs. $60.6 \pm 13$, p $<0.001)$, with a greater proportion over 80 years of age. Regarding cardiovascular risk factors, females had higher rates of diabetes and hypertension and were less likely to smoke. Females also had less frequent history of coronary disease or bypass surgery. They were less likely to call an emergency dispatch center. Early medication 
upstream of hospital admission, administered on the way to hospital, differed notably, with less administration in women not only of GPIIbIIIa inhibitors, but also of P2Y12 inhibitors (clopidogrel, prasugrel or ticagrelor) and even aspirin.

Emergency myocardial revascularization was performed in 14,137 patients $(86.8 \%): 10,970(67.4 \%)$ by pPCI, $944(5.8 \%)$ by fibrinolysis and $13.6 \%$ by fibrinolysis followed by rescue PCI (Table 1). Type of reperfusion differed significantly according to gender: pPCI was more frequent than fibrinolysis in women.

2149 patients received no reperfusion therapy (neither fibrinolysis nor pPCI): $18.3 \%$ of women and $11.6 \%$ of men $(\mathrm{p}<0.001)$.

\section{Delays}

To better understand the complex relationship between gender and delay, the various components of delay were examined separately, as reported in eTable 2. Firstly, patient delay was longer in women, with a mean difference of $20 \mathrm{~min}$, whatever the type of first medical contact sought: dispatch center call, or direct arrival in an emergency department. Interestingly, more women experienced absence of recommendation after calling the dispatch center and then presented themselves to the ED after having called (20.7\% vs $11.5 \%)$ resulting in significant longer patient delay, even after adjustment. Even with the shorter recommended dispatch center care process, women waited more than 20 minutes before seeking treatment. This difference was found regardless of the age group, except for those under 50 (Figure 1A) and was stable over time (Figure 1B). Risk factors for longer patient delays were age over 70, female sex and diabetes (online supplement eTable 3). The time elapsed between the first medical contact and the reperfusion did not significantly differ with gender (online supplement, eTable2). Whereas system delay appeared not to significantly differ between genders, initial patient delay significantly impacted total ischemic time,. As a result, the overall ischemic time mean difference between genders was 16 minutes before and 19 minutes after adjustment. This difference seemed particularly to affect women in case of pPCI, but only in non-adjusted analysis. 
As reported in eTable 2, after adjustment on clinical characteristics such as age and risk factors, only time difference in patient delay persisted, where the mean difference was 14 minutes longer in women.

\section{In-hospital mortality}

In this collection of pooled patient data, in-hospital mortality was 2.4 times higher in women than men. Global in-hospital mortality was $9.6 \%$ in women and $3.9 \%$ in men ( $p<0.001)$. In-hospital mortality did not vary substantially over the inclusion period from 2005 to 2012 . Nor was there any significant difference according to the geographical regions of the various registries. On the other hand, in-hospital mortality varied not only according to gender but also to age, as reported in Figure 2.

Predictive factors for in-hospital mortality are presented in Table 2. On univariable analysis, the main predictors were gender, age, diabetes, smoking and hypertension, whereas PPCI appeared to be protective. However, on multivariable analysis, only gender, age and most of all diabetes remained as predictive factors.

\section{Discussion}

The present study, based on a unique French collection of pooled patient data, analyzed the impact of gender on delays and in-hospital mortality in STEMI patients between 2005 and 2012. Sex differences in outcome were previously reported ${ }^{3-14}$, but it remained unclear whether this represented a true difference in the biology of the disease or was rather due to confounding differences in baseline factors: cardiovascular risk profile and/or health-care utilization. The present analysis of 16,733 prospectively included patients had the statistical power to progress in decoding this gender gap.

\section{Delays}

The first finding was that, of the various components of delay, only patient delay differed between genders on multivariable analysis. Similar findings had been reported in the Canadian comparative cohort study ${ }^{15}$. Conversely, system delay and ischemic time were not significantly influenced by 
gender after adjustment, which is reassuring from the point of view of medical support quality. A Dutch multicenter study reported longer ischemic time in women treated by pPCI for STEMI, with longer diagnosis-to-balloon time ${ }^{21}$ on univariate analysis, multivariate analysis revealing that this delay was mainly prolonged by age and comorbidity. In our study, ischemic time was split into its two main components: patient delay (call time) and system delay. This point is important to clarify and guide future improvement programs targeting women in order to improve their awareness and accelerate their care-seeking response to symptoms ${ }^{16}$. A recent qualitative study ${ }^{35}$ found that women, and particularly younger ones, did not accurately assess their cardiovascular risk, contributing to delay in identifying MI symptoms and thus impacting the health-care system. The Canadian study showed that patient education campaigns could be effective in improving patient awareness and affecting response to symptoms ${ }^{16}$. A recent retrospective study including 2297 STEMI patient analyzed characteristics associated with prolonged ischemic time, they found that self-presentation, and unmarried women had longer delays ${ }^{36}$.

The present study included only STEMI patients presenting in an emergency department with PCI facilities or else managed by MICU; cases involving interhospital transfer were excluded, to minimize bias. Thus the results do not show longer system delay for women, as previously reported, especially in terms of lower priority for MICU management ${ }^{24}$ and higher rates of overlooked pre-hospital STEMI diagnosis ${ }^{37}$. The recent Swiss study observed, in of 4723 patients presented with acute MI, discrimination of elderly patients and females in the provision of $\mathrm{pPCI}{ }^{38}$. Likewise the American observational study of young MI patients VIRGO ${ }^{39}$ found that young female are less likely to receive reperfusion therapy and have more reperfusion delays than similarly aged men, particularly among patients transferred to PCI as previously reported ${ }^{40}$. But the latest were not included in our study. Our French large analysis, supports that longer ischemic times are directly linked to the patient's delay in calling, with limited possibilities of improvement in the medical care process in this setting of patients.

\section{Invasive therapies}


Though the difference in mortality rate between men and women with acute MI is largely due to differences in age and comorbidities, reperfusion strategy may also be involved. In fact, the impact of gender on the implementation of invasive strategies was one of the first gender discrepancies to be described, in the early $1990 \mathrm{~s}^{41}$, and still reported even in the 2000s $5,9,22,23,42-45$. Moreover, treatment modality was shown to partly explain the poorer prognosis found in women experiencing STEMI. Microsimulation analysis performed on the 1999 Nationwide French Hospitals Database suggested that women would derive benefit from more frequent use of $\mathrm{PCI}^{7}$. However propensity score analysis, with matching on both baseline characteristics and treatment, showed comparable 30-day mortality between genders ${ }^{11}$. Compared to these studies, we found a higher rate of invasive strategy, especially in favor of pPCI. The higher rate of pPCI could also be related to the inclusion criteria. Nonetheless, multivariate analysis in the present large population showed that this did not contribute to increased mortality (Table 2).

\section{Mortality}

The second finding is that female gender showed a 2.5 -fold increased crude in-hospital mortality. This disadvantage persisted after adjustment on age, year of inclusion, therapeutic strategy and even delay

(Table 2). No heterogeneity in mortality according to gender was found between geographical regions. Similarly, the recent meta-analysis by Pancholy et al. ${ }^{8}$ reported mortality in women with STEMI treated by pPCI to be nearly 2 -fold higher than in men. As in our study, women with STEMI had a poorer baseline cardiovascular risk profile, tended to be older at presentation, and had higher prevalence of diabetes and high blood pressure. Using adjusted models, the mortality remained high in women as compared to men. However, this meta-analysis was not performed on individual data and risk estimates might have been biased despite adjustment. Conversely, as our analysis was performed on patient-level data without restriction in individual data, the strength of our estimates is reinforced. An interesting hypothesis raised by Pancholy ${ }^{8}$ was that women seek medical care only in the more severe cases, otherwise tending to minimize symptoms and not reach the health-care system. We were 
unable to explore this hypothesis as current studies and registries are not designed to explore this consideration. The present observational data does also not provide any causal account. Thus, these preliminary results confirm gender disparity, but are hypothesis-generating and need large-scale prospective confirmation. Further prospective data collections are mandatory to explore the underlying mechanisms.

To our knowledge, this study is the first comprehensive large-scale patient-level analysis not only of in-hospital mortality but also of ischemic time components in STEMI.

The strengths of our Metaregistry include the patient-level analysis, which makes our findings particularly robust as they derive from individual patient-level data from prospective registries, with data monitoring. Secondly, data were collected over a long period and from a diversity of regions. Finally, the narrow and well defined exposure measures (STEMI $<12 \mathrm{~h}$, with first medical contact in an emergency department with PCI facility or MICU) and outcome measures (patient and system delays and in-hospital mortality) limit the risk of measurement error.

Nevertheless this pooled analysis had several limitations. First, regarding investigation of gender differences, the observational design could not rule out unknown confounding factors. Furthermore, for homogeneity in the population, we decided to exclude patients presenting after 12 hours of symptoms, out of hospital cardiac arrest and patients transferred from non PCI hospital, thereby limiting to depict real-world difference. Second, only all-cause mortality was reported, rather than specific cardiovascular mortality, owing to the lack of specific data. Likewise, data regarding vascular access, bivalirudin or heparin use were not reported in most of the registries. Moreover, one frequent in-hospital complication known in women is bleeding, in particular after fibrinolytic therapy ${ }^{10}$, and this variable was not recorded in most of the registries. Future prospective studies would have to itemize this complication.

For the first time, the present study provides an overview of 16,733 real-life consecutive STEMI patients prospectively included in the 7 main French registries from 2005 to 2012 . The results strongly support a discrepancy between women and men, emphasizing clinically relevant longer delays in 
seeking medical attention. However, the crude 2.4-fold higher in-hospital mortality rate of women cannot be explained solely by delays, and persists with a nearly 2-fold higher risk even after adjustments. This result highlights the need for dedicated prospective studies to determine the specific mechanisms underlying this excess risk associated with female gender and to develop appropriate measures to optimize the health-care process and prevention in women to reduce this gender gap. 


\section{Acknowledgments}

We would like to thank the team of clinical research assistants from the registries who ensured data collection, selected the data and made sure of their quality. We also would like to thank the cardiologists and emergency and MICU physicians and staff who cared for and saved the lives of patients while collecting data.

Last but not least, we thank all the patients who have agreed to participate in the different regsitres. Without their authorizations to work on their data, we could not progress in understanding the mechanisms underlying the observed differences in prognosis. The authors are also indebted to Catherine Tanqueray, who enabled the authors to meet and work together, supported by her enthusiasm.

Funding: none 
1. Go AS, Mozaffarian D, Roger VL, Benjamin EJ, Berry JD, Borden WB, Bravata DM, Dai S, Ford ES, Fox CS, Franco S, Fullerton HJ, Gillespie C, Hailpern SM, Heit JA, Howard VJ, Huffman MD, Kissela BM, Kittner SJ, Lackland DT, Lichtman JH, Lisabeth LD, Magid D, Marcus GM, Marelli A, Matchar DB, McGuire DK, Mohler ER, Moy CS, Mussolino ME, Nichol G, Paynter NP, Schreiner PJ, Sorlie PD, Stein J, Turan TN, Virani SS, Wong ND, Woo D, Turner MB. Heart disease and stroke statistics--2013 update: a report from the American Heart Association. Circulation 2013;127:e6-e245.

2. Townsend N, Wilson L, Bhatnagar P, Wickramasinghe $K$, Rayner $M$, Nichols $M$. Cardiovascular disease in Europe: epidemiological update 2016. Eur Heart $J$ 2016;37:3232-3245.

3. Berger JS, Elliott L, Gallup D, Roe M, Granger CB, Armstrong PW, Simes RJ, White HD, Van de Werf F, Topol EJ, Hochman JS, Newby LK, Harrington RA, Califf RM, Becker RC, Douglas PS. Sex differences in mortality following acute coronary syndromes. Jama 2009;302:874-82.

4. De Luca G, Suryapranata H, Dambrink JH, Ottervanger JP, van 't Hof AW, Zijlstra F, Hoorntje JC, Gosselink AT, de Boer MJ. Sex-related differences in outcome after ST-segment elevation myocardial infarction treated by primary angioplasty: data from the Zwolle Myocardial Infarction study. Am Heart J 2004;148:852-6.

5. Hasdai D, Porter A, Rosengren A, Behar S, Boyko V, Battler A. Effect of gender on outcomes of acute coronary syndromes. Am J Cardiol 2003;91:1466-9, A6.

6. Kosuge M, Kimura K, Kojima S, Sakamoto T, Ishihara M, Asada Y, Tei C, Miyazaki S, Sonoda M, Tsuchihashi K, Yamagishi M, Ikeda Y, Shirai M, Hiraoka H, Inoue T, Saito F, Ogawa H. Sex differences in early mortality of patients undergoing primary stenting for acute myocardial infarction. Circ J 2006;70:217-21.

7. Milcent C, Dormont B, Durand-Zaleski I, Steg PG. Gender differences in hospital mortality and use of percutaneous coronary intervention in acute myocardial infarction: microsimulation analysis of the 1999 nationwide French hospitals database. Circulation 2007;115:833-9.

8. Pancholy SB, Shantha GP, Patel T, Cheskin U. Sex differences in short-term and long-term allcause mortality among patients with ST-segment elevation myocardial infarction treated by primary percutaneous intervention: a meta-analysis. JAMA Intern Med 2014;174:1822-30.

9. Radovanovic D, Erne P, Urban P, Bertel O, Rickli H, Gaspoz JM. Gender differences in management and outcomes in patients with acute coronary syndromes: results on 20,290 patients from the AMIS Plus Registry. Heart 2007;93:1369-75.

10. Reynolds HR, Farkouh ME, Lincoff AM, Hsu A, Swahn E, Sadowski ZP, White JA, Topol EJ, Hochman JS. Impact of female sex on death and bleeding after fibrinolytic treatment of myocardial infarction in GUSTO V. Arch Intern Med 2007;167:2054-60.

11. Schiele F, Meneveau N, Seronde MF, Descotes-Genon V, Chopard R, Janin S, Briand F, Guignier $A$, Ecarnot F, Bassand JP. Propensity score-matched analysis of effects of clinical characteristics and treatment on gender difference in outcomes after acute myocardial infarction. Am J Cardiol 2011;108:789-98.

12. Vaccarino V, Horwitz RI, Meehan TP, Petrillo MK, Radford MJ, Krumholz HM. Sex differences in mortality after myocardial infarction: evidence for a sex-age interaction. Arch Intern Med 1998;158:2054-62.

13. Vaccarino V, Parsons L, Every NR, Barron HV, Krumholz HM. Sex-based differences in early mortality after myocardial infarction. National Registry of Myocardial Infarction 2 Participants. $\mathbf{N}$ Engl J Med 1999;341:217-25.

14. Leurent G, Garlantezec R, Auffret V, Hacot JP, Coudert I, Filippi E, Rialan A, Moquet B, Rouault G, Gilard M, Castellant P, Druelles P, Boulanger B, Treuil J, Avez B, Bedossa M, Boulmier D, Le Guellec M, Le Breton H. Gender differences in presentation, management and inhospital outcome in patients with ST-segment elevation myocardial infarction: data from $\mathbf{5 0 0 0}$ patients included in the ORBI prospective French regional registry. Arch Cardiovasc Dis 2014;107:291-8. 
15. Zanchi J, Miric D, Giunio L, Vukovic I, Markovic B, Duplancic D, Kristic I. Gender differences in inhospital mortality and angiographic findings of patients with acute ST-segment elevation myocardial infarction (STEMI) undergoing percutaneous coronary intervention (PCI). Coll Antropol 2009;33:1359-62.

16. Kaul P, Armstrong PW, Sookram S, Leung BK, Brass N, Welsh RC. Temporal trends in patient and treatment delay among men and women presenting with ST-elevation myocardial infarction. Am Heart J 2011;161:91-7.

17. Gupta A, Wang Y, Spertus JA, Geda M, Lorenze N, Nkonde-Price C, D'Onofrio G, Lichtman JH, Krumholz HM. Trends in acute myocardial infarction in young patients and differences by sex and race, 2001 to 2010. J Am Coll Cardiol 2014;64:337-45.

18. Champney KP, Frederick PD, Bueno H, Parashar S, Foody J, Merz CN, Canto JG, Lichtman JH, Vaccarino $V$. The joint contribution of sex, age and type of myocardial infarction on hospital mortality following acute myocardial infarction. Heart 2009;95:895-9.

19. Kyto V, Sipila J, Rautava P. Gender and in-hospital mortality of ST-segment elevation myocardial infarction (from a multihospital nationwide registry study of 31,689 patients). Am J Cardiol 2014;115:303-6.

20. Akhter N, Milford-Beland S, Roe MT, Piana RN, Kao J, Shroff A. Gender differences among patients with acute coronary syndromes undergoing percutaneous coronary intervention in the American College of Cardiology-National Cardiovascular Data Registry (ACC-NCDR). Am Heart J 2009;157:141-8.

21. Velders MA, Boden H, van Boven AJ, van der Hoeven BL, Heestermans AA, Cannegieter SC, Umans VA, Jukema JW, Hofma SH, Schalij MJ. Influence of gender on ischemic times and outcomes after ST-elevation myocardial infarction. Am J Cardiol 2013;111:312-8.

22. Vaccarino V, Rathore SS, Wenger NK, Frederick PD, Abramson JL, Barron HV, Manhapra A, Mallik S, Krumholz HM. Sex and racial differences in the management of acute myocardial infarction, 1994 through 2002. N Engl J Med 2005;353:671-82.

23. Hvelplund A, Galatius $S$, Madsen M, Rasmussen JN, Rasmussen S, Madsen JK, Sand NP, Tilsted $\mathrm{HH}$, Thayssen P, Sindby E, Hojbjerg S, Abildstrom SZ. Women with acute coronary syndrome are less invasively examined and subsequently less treated than men. Eur Heart $J$ 2010;31:684-90.

24. Melberg T, Kindervaag B, Rosland J. Gender-specific ambulance priority and delays to primary percutaneous coronary intervention: a consequence of the patients' presentation or the management at the emergency medical communications center? Am Heart J 2013;166:839-45.

25. Mehilli J, Kastrati A, Dirschinger J, Pache J, Seyfarth M, Blasini R, Hall D, Neumann FJ, Schomig A. Sex-based analysis of outcome in patients with acute myocardial infarction treated predominantly with percutaneous coronary intervention. Jama 2002;287:210-5.

26. Gibson CM. Time is myocardium and time is outcomes. Circulation 2001;104:2632-4.

27. Steg PG, Bonnefoy E, Chabaud S, Lapostolle F, Dubien PY, Cristofini P, Leizorovicz A, Touboul P. Impact of time to treatment on mortality after prehospital fibrinolysis or primary angioplasty: data from the CAPTIM randomized clinical trial. Circulation 2003;108:2851-6.

28. De Luca G, Suryapranata H, Ottervanger JP, Antman EM. Time delay to treatment and mortality in primary angioplasty for acute myocardial infarction: every minute of delay counts. Circulation 2004;109:1223-5.

29. Brodie BR, Stuckey TD, Muncy DB, Hansen CJ, Wall TC, Pulsipher M, Gupta N. Importance of time-to-reperfusion in patients with acute myocardial infarction with and without cardiogenic shock treated with primary percutaneous coronary intervention. Am Heart J 2003;145:708-15.

30. Brodie BR, Stone GW, Cox DA, Stuckey TD, Turco M, Tcheng JE, Berger P, Mehran R, McLaughlin M, Costantini C, Lansky AJ, Grines CL. Impact of treatment delays on outcomes of primary percutaneous coronary intervention for acute myocardial infarction: analysis from the CADILLAC trial. Am Heart J 2006;151:1231-8.

31. Brodie BR, Gersh BJ, Stuckey T, Witzenbichler B, Guagliumi G, Peruga JZ, Dudek D, Grines CL, Cox D, Parise H, Prasad A, Lansky AJ, Mehran R, Stone GW. When is door-to-balloon time critical? Analysis from the HORIZONS-AMI (Harmonizing Outcomes with Revascularization and Stents in 
Acute Myocardial Infarction) and CADILLAC (Controlled Abciximab and Device Investigation to Lower Late Angioplasty Complications) trials. J Am Coll Cardiol 2010;56:407-13.

32. Boersma E. Does time matter? A pooled analysis of randomized clinical trials comparing primary percutaneous coronary intervention and in-hospital fibrinolysis in acute myocardial infarction patients. Eur Heart J 2006;27:779-88.

33. Puymirat E, Simon T, Steg PG, Schiele F, Gueret P, Blanchard D, Khalife K, Goldstein P, Cattan S, Vaur L, Cambou JP, Ferrieres J, Danchin N. Association of changes in clinical characteristics and management with improvement in survival among patients with ST-elevation myocardial infarction. Jama 2012;308:998-1006.

34. Steg PG, James SK, Atar D, Badano LP, Blomstrom-Lundqvist C, Borger MA, Di Mario C, Dickstein K, Ducrocq G, Fernandez-Aviles F, Gershlick AH, Giannuzzi $P$, Halvorsen $S$, Huber $K$, Juni $P$, Kastrati A, Knuuti J, Lenzen MJ, Mahaffey KW, Valgimigli M, van 't Hof A, Widimsky P, Zahger D. ESC Guidelines for the management of acute myocardial infarction in patients presenting with STsegment elevation. Eur Heart J 2012;33:2569-619.

35. Lichtman JH, Leifheit-Limson EC, Watanabe E, Allen NB, Garavalia B, Garavalia LS, Spertus JA, Krumholz HM, Curry LA. Symptom recognition and healthcare experiences of young women with acute myocardial infarction. Circ Cardiovasc Qual Outcomes 2015;8:S31-8.

36. Austin D, Yan AT, Spratt JC, Kunadian V, Edwards RJ, Egred M, Bagnall AJ. Patient characteristics associated with self-presentation, treatment delay and survival following primary percutaneous coronary intervention. Eur Heart J Acute Cardiovasc Care 2014;3:214-22.

37. Mahmoud KD, Gu YL, Nijsten MW, de Vos R, Nieuwland W, Zijlstra F, Hillege HL, van der Horst IC, de Smet BJ. Interhospital transfer due to failed prehospital diagnosis for primary percutaneous coronary intervention: an observational study on incidence, predictors, and clinical impact. Eur Heart J Acute Cardiovasc Care 2013;2:166-75.

38. Pilgrim T, Heg D, Tal K, Erne P, Radovanovic D, Windecker S, Juni P. Age- and Gender-related Disparities in Primary Percutaneous Coronary Interventions for Acute ST-segment elevation Myocardial Infarction. PLoS One 2015;10:e0137047.

39. D'Onofrio G, Safdar B, Lichtman JH, Strait KM, Dreyer RP, Geda M, Spertus JA, Krumholz HM. Sex differences in reperfusion in young patients with ST-segment-elevation myocardial infarction: results from the VIRGO study. Circulation 2015;131:1324-32.

40. Wang TY, Nallamothu BK, Krumholz HM, Li S, Roe MT, Jollis JG, Jacobs AK, Holmes DR, Peterson ED, Ting HH. Association of door-in to door-out time with reperfusion delays and outcomes among patients transferred for primary percutaneous coronary intervention. JAMA 2011;305:2540-7.

41. Ayanian JZ, Epstein AM. Differences in the use of procedures between women and men hospitalized for coronary heart disease. N Engl J Med 1991;325:221-5.

42. Hochman JS, Tamis JE, Thompson TD, Weaver WD, White HD, Van de Werf F, Aylward P, Topol EJ, Califf RM. Sex, clinical presentation, and outcome in patients with acute coronary syndromes. Global Use of Strategies to Open Occluded Coronary Arteries in Acute Coronary Syndromes IIb Investigators. N Engl J Med 1999;341:226-32.

43. Anand SS, Xie CC, Mehta S, Franzosi MG, Joyner C, Chrolavicius S, Fox KA, Yusuf S. Differences in the management and prognosis of women and men who suffer from acute coronary syndromes. J Am Coll Cardiol 2005;46:1845-51.

44. Alfredsson J, Stenestrand U, Wallentin L, Swahn E. Gender differences in management and outcome in non-ST-elevation acute coronary syndrome. Heart 2007;93:1357-62.

45. Dey S, Flather MD, Devlin G, Brieger D, Gurfinkel EP, Steg PG, Fitzgerald G, Jackson EA, Eagle KA. Sex-related differences in the presentation, treatment and outcomes among patients with acute coronary syndromes: the Global Registry of Acute Coronary Events. Heart 2009;95:20-6. 


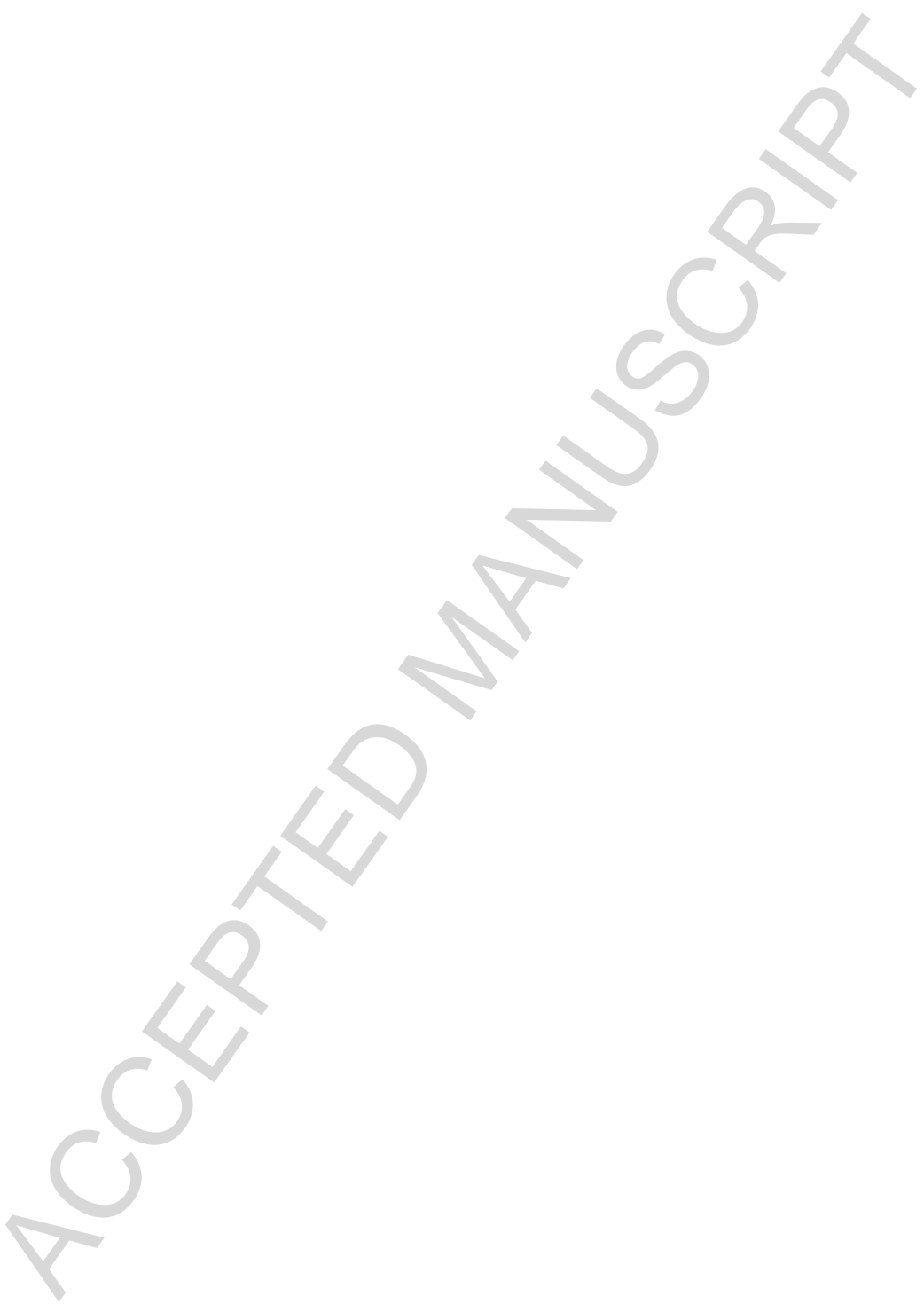


Table 1: Patient characteristics

\begin{tabular}{|c|c|c|c|c|}
\hline & $\begin{array}{l}\text { Men } \\
(\mathrm{N}=12,712)\end{array}$ & $\begin{array}{l}\text { Women } \\
(\mathrm{N}=4,021)\end{array}$ & $\begin{array}{l}\text { TOTAL } \\
(\mathrm{N}=16,733)\end{array}$ & $\begin{array}{l}\mathbf{P} \\
\text { value }\end{array}$ \\
\hline \multicolumn{5}{|l|}{ Registry $\mathrm{n}(\%)$} \\
\hline FAST 2010 & $978(76.4)$ & $302(23.6)$ & 1,280 & \\
\hline F comt & $1,344(70.1)$ & 573 (29.9) & 1,917 & \\
\hline ORBI & $3,122(77.4)$ & $911(22.6)$ & 4,033 & \\
\hline Resca31+ & $369(75.8)$ & $118(24.2)$ & 487 & 0.48 \\
\hline RESCUe & $3,003(76.2)$ & $937(23.8)$ & 3,940 & \\
\hline RESURCOR & $2,983(78.3)$ & $828(21.7)$ & 3,811 & \\
\hline RICO & $913(72.2)$ & $352(27.8)$ & 1,265 & \\
\hline \multicolumn{5}{|l|}{ Clinical characteristics } \\
\hline $\begin{array}{l}\text { Age }(\text { mean } \pm \text { SD) } \\
\qquad \begin{array}{l}\text { Age }<50 \text { years } n(\%) \\
\text { Age }>80 \text { years } n(\%)\end{array}\end{array}$ & $\begin{array}{l}60.6 \pm 13.2 \\
2785(86.8) \\
1,152(46.5)\end{array}$ & $\begin{array}{l}70.6 \pm 14.3 \\
424(13.2) \\
1,327(53.5)\end{array}$ & $\begin{array}{l}63 \pm 14.2 \\
3,209 \\
2,479\end{array}$ & $<0.001$ \\
\hline $\begin{array}{l}\text { Type-2 Diabetes* } n(\%) \\
\mathrm{N}=12,764\end{array}$ & $1,476(15.4)$ & $623(19.6)$ & $2,099(16.4)$ & $<0.001$ \\
\hline $\begin{array}{l}\mathbf{H B P}^{*} \mathrm{n}(\%) \\
\mathrm{N}=12,511\end{array}$ & $3,651(38.8)$ & $1,826(58.7)$ & $5,477(43.8)$ & $<0.001$ \\
\hline $\begin{array}{l}\text { Current smoker* } \mathrm{n}(\%) \\
\mathrm{N}=12,848\end{array}$ & $4,475(46.2)$ & $820(25.9)$ & $5,295(41.2)$ & $<0.001$ \\
\hline $\begin{array}{l}\text { Previous CAD* n (\%) } \\
\mathrm{N}=16,366\end{array}$ & 2,466 (19.9) & $662(16.8)$ & $3,128(19.1)$ & $<0.001$ \\
\hline $\begin{array}{l}\text { Previous CABG* } \mathrm{n}(\%) \\
\mathrm{N}=12,768\end{array}$ & $350(3.6)$ & $87(2.8)$ & $437(3.4)$ & 0.03 \\
\hline ST-elevation & & & & \\
\hline
\end{tabular}




\begin{tabular}{|c|c|c|c|c|}
\hline management & & & & \\
\hline $\begin{array}{l}\text { Use of emergency call } \\
\text { number } n(\%)\end{array}$ & $8,729(68.7)$ & $2,555(63.5)$ & $11,284(67.4)$ & $<0.001$ \\
\hline $\begin{array}{l}\text { Pre-hospital aspirin } n \\
(\%)\end{array}$ & $7,278(94.9)$ & 2,177 ( 93.4) & $9,455(94.6)$ & 0.018 \\
\hline $\mathrm{N}=10,000$ & & & & \\
\hline $\begin{array}{ll}\text { Pre-hospital } & \text { P2Y12 } \\
\text { inhibitors n (\%) } & \end{array}$ & $6,457(87.7)$ & $1,916(85)$ & $8,373(87.1)$ & 0.004 \\
\hline $\mathrm{N}=9,616$ & & & & \\
\hline $\begin{array}{l}\text { Pre-hospital GPIIbIIIa } \\
\text { inhibitors n (\%) }\end{array}$ & $2,783(33.5)$ & 716 & $3,499(32.3)$ & $<0.001$ \\
\hline $\mathrm{N}=10,837$ & & & & \\
\hline Reperfusion n (\%) & & & & $<0.001$ \\
\hline Fibrinolysis only & $774(6.2)$ & $170(4.4)$ & $944(5.8)$ & \\
\hline Primary PCI & $8,396(67$. & $2,574(66.7)$ & $10,970(67.4)$ & \\
\hline Rescue PCI & $1,815(14.6$ & $408(10.6)$ & $2,223(13.6)$ & \\
\hline No reperfusion & $1,442(11.6)$ & $707(18.3)$ & $2,149(13.2)$ & \\
\hline
\end{tabular}

$* N$ indicates the number of patients with available data

CABG: coronary aortic bypass grafting; CAD: coronary artery disease; HBP: High Blood Pressure; PCI: percutaneous coronary intervention; SD: standard deviation 
Table 2: Univariable and multivariable predictors of mortality

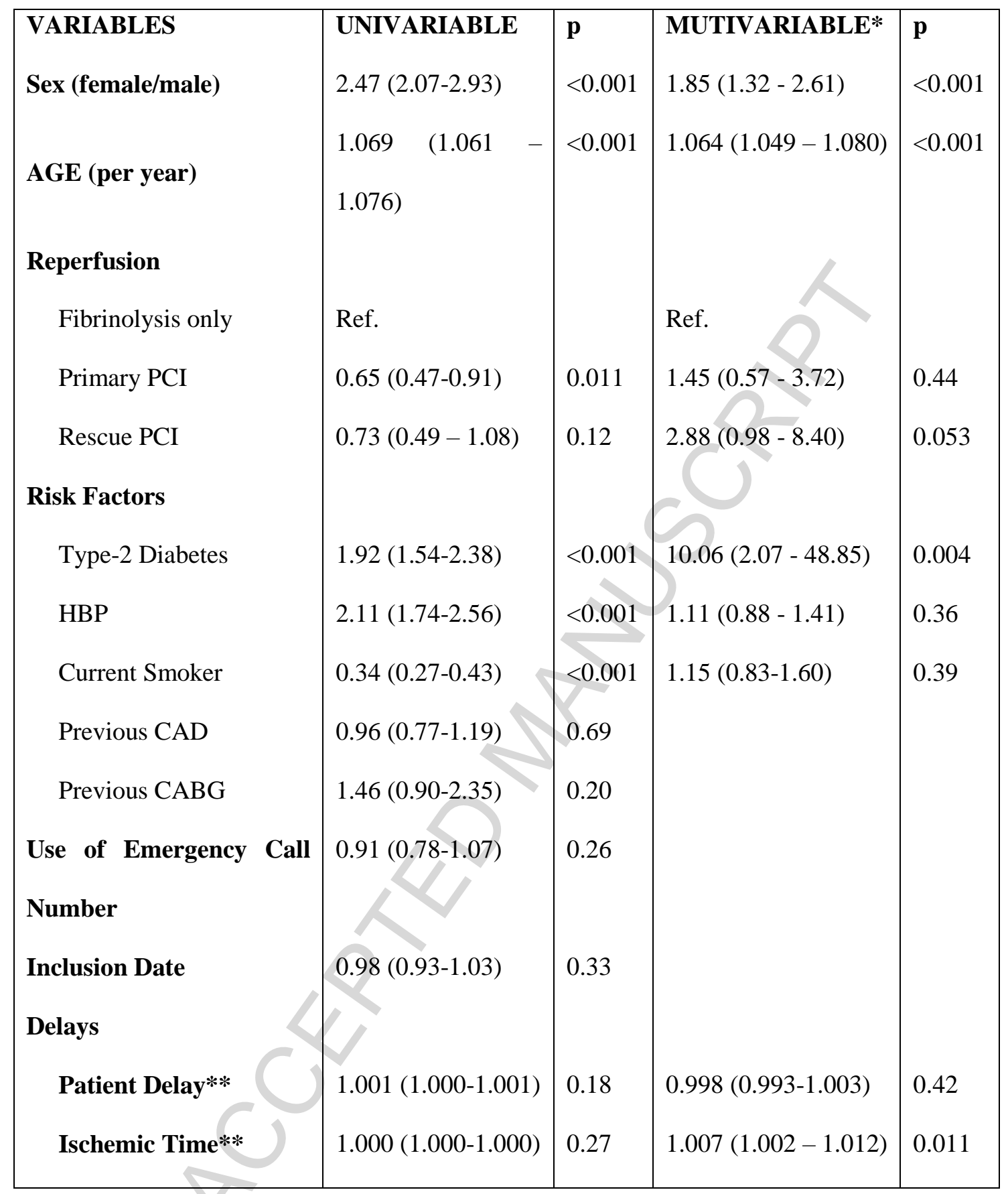

CABG: coronary aortic bypass grafting; CAD: coronary artery disease; HBP: High Blood Pressure; PCI: percutaneous coronary intervention 
*In the multivariable analysis, all significant interactions were included in the model ([ischemic time and reperfusion, $\mathrm{p}=0.022$ ], [patient delay and age, $\mathrm{p}=0.03$ ], [patient delay and gender, $\mathrm{p}=0.047$ ], [gender and smoking status, $\mathrm{p}=0.02$ ], [age and diabetes, $\mathrm{p}=0.009$ ])

** Although the patient delay and ischemic time variables were not found to be significantly associated with an increased risk of death on univariable analysis, these variables were included in the multivariate model as they were found to be in interaction with other variables

No difference was found comparing registries 
Figure legends

Figure 1: Patient delay according to age (A) and year of inclusion $(B)$. ( mean $\pm 95 \% \mathrm{CI}$; ANOVA $p<0.001$ for each figure)

Figure 2: In-hospital mortality rate according to age in deciles. Univariate odds ratio and interquartile range for in-hospital mortality 


\section{HIGHLIGHTS}

Question: In contemporary area of STEMI care process, does gender independently impact time management and in-hospital mortality?

Findings: This French Metaregister pooling 16,733 patients showed that patient delay is indeed significantly longer in women whereas the system delay did not differ. Women experienced in-hospital death $2 \cdot 4$ times more often, this disadvantage persisted after adjustments.

Meaning: Discrepancy between women and men with STEMI still highlighting the need for dedicated prospective studies to determine the specific mechanisms underlying this excess risk and to optimize the health-care process to reduce this gender gap. 
A

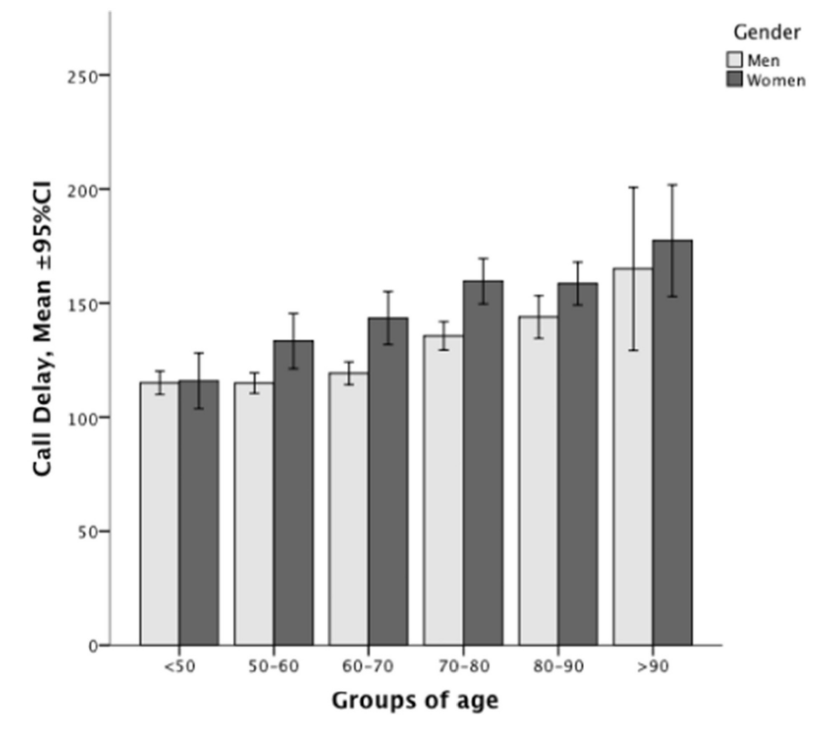

\begin{tabular}{|l|c|c|c|c|c|c|}
\hline & $<50$ & $50-59$ & $60-69$ & $70-79$ & $80-89$ & $>90$ \\
\hline Female (n) & 416 & 521 & 642 & 1028 & 1072 & 180 \\
Male (n) & 2736 & 3439 & 2957 & 2187 & 1022 & 85 \\
\hline
\end{tabular}

B

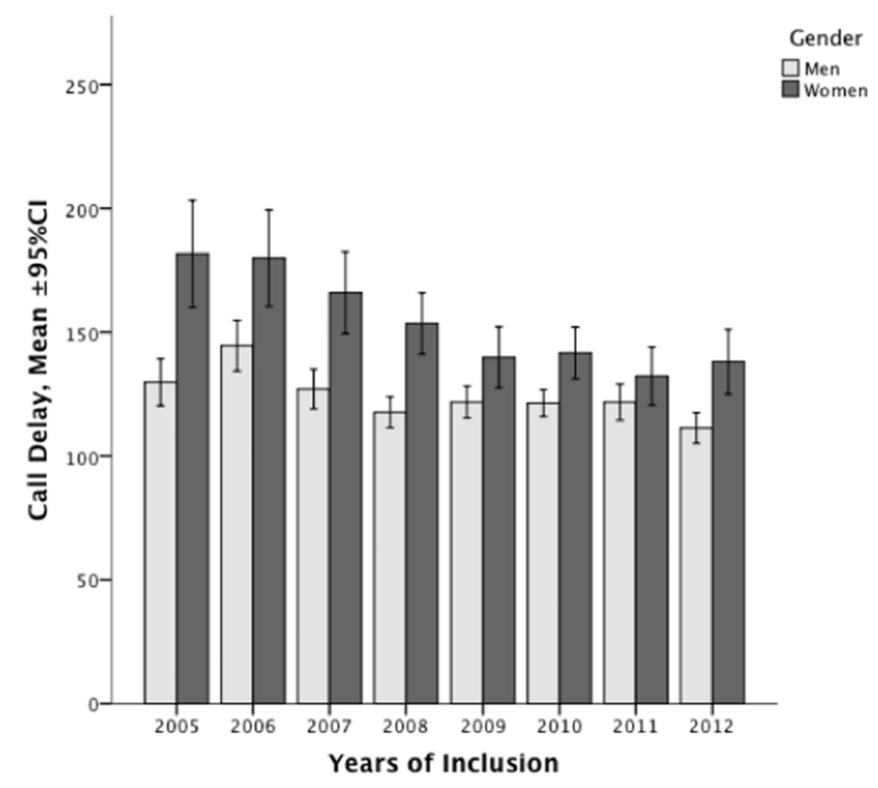

\begin{tabular}{|l|c|c|c|c|c|c|c|c|}
\hline & 2005 & 2006 & 2007 & 2008 & 2009 & 2010 & 2011 & 2012 \\
\hline Female (n) & 268 & 276 & 358 & 556 & 566 & 817 & 507 & 511 \\
Male (n) & 900 & 889 & 1182 & 1717 & 1798 & 2626 & 1524 & 1791 \\
\hline
\end{tabular}

Figure 1 




\section{Men}

Women

\begin{tabular}{|l|l|l|l|l|l|l|}
\hline & $<50$ & $50-59$ & $60-69$ & $70-79$ & $80-89$ & $>90$ \\
\hline Fale (n) & 2423 & 2948 & 3110 & 1921 & 1860 & 84 \\
\hline OR & ref & 1.44 & 2.11 & 4.59 & 11.24 & 20.35 \\
\hline IC & & 463 & 589 & 937 & 1024 & 174 \\
& & $0.99-$ & $1.47-$ & $3.27-$ & $8.07-$ & $13.29-$ \\
\hline P value & & 2.12 & 3.04 & 6.45 & 15.64 & 31.16 \\
& & & & & & $<0.001$ \\
\hline
\end{tabular}

Figure 2 